\title{
Caracterização de cultivares de pessegueiro e de nectarineira por marcadores moleculares ${ }^{(1)}$
}

\author{
Marli Rocha Lima ${ }^{(2)}$, Eliane Augustin ${ }^{(3)}$, Eva Choer ${ }^{(3)}$ e Maria do Carmo Bassols Raseira ${ }^{(3)}$
}

Resumo - Em espécies de estreita base genética, como o pessegueiro e a nectarineira (Prunus persica (L.) Batsch), a utilização de marcadores moleculares para a caracterização de cultivares é de grande importância, além do potencial de uso para fins de proteção. As técnicas de eletroforese em gel e RAPD foram empregadas com o objetivo de caracterizar as cultivares de pessegueiro Granada, Esmeralda, Jade, Eldorado, Riograndense, Capdeboscq, Aldrighi, Precocinho, Diamante, Turmalina, Maciel, BR-1, Pepita, Coral, Chinoca, Marfim, Chiripá, Della Nona e Planalto, e as de nectarineira Dulce e Anita. Foram analisadas isoenzimas de 6-fosfogluconato desidrogenase e fosfatase ácida em pólen, peroxidase, fosfoglucoisomerase, aspartato transaminase e isocitrato desidrogenase em folhas, e malato desidrogenase, leucina aminopeptidase e fosfoglucomutase em pólen e folhas. Dos 50 primers testados, 11 foram escolhidos para análise de RAPD em folhas. As análises de similaridade e de agrupamento entre os genótipos foram feitas empregando-se o coeficiente de Jaccard e o método da média aritmética não ponderada. Apesar das diferenças detectadas nas isoenzimas de malato desidrogenase em pólen e folhas de pessegueiro e nectarineira, o baixo polimorfismo apresentado pelos demais sistemas não permitiu a caracterização de todas as cultivares por essa técnica. Os marcadores RAPD, associados ou não à eletroforese de isoenzimas, foram eficientes para caracterizar as cultivares de pessegueiro e nectarineira.

Termos para indexação: Prunus persica, eletroforese, isoenzimas, polimorfismo genético.

\section{Characterization of peach and nectarine cultivars through molecular markers}

Abstract - In species with a narrow genetic basis, such as peach and nectarine (Prunus persica (L.) Batsch), the utilization of molecular markers in cultivar characterization is very important, besides the potential of use for protection. Gel electrophoresis and RAPD techniques were used to characterize peach cultivars Granada, Esmeralda, Jade, Eldorado, Riograndense, Capdeboscq, Aldrighi, Precocinho, Diamante, Turmalina, Maciel, BR-1, Pepita, Coral, Chinoca, Marfim, Chiripá, Della Nona and Planalto and nectarine cultivars Dulce and Anita. Isoenzymes of 6-phosphogluconate dehydrogenase and acid phosphatase in pollen, peroxidase, phosphoglucoisomerase, aspartate transaminase and isocitrate dehydrogenase in leaves, malate dehydrogenase, leucine aminopeptidase and phosphoglucomutase in pollen and leaves were analyzed. Fifty primers were tested and eleven were used to analyze RAPD markers in leaf extracts. Similarity and cluster analysis were conducted using Jaccard coefficient and the unweighted pair group method with arithmetic average. Despite the differences detected in malate dehydrogenase in peach and nectarine pollen and leaves, the low polymorphism presented by the other systems did not allow the characterization of all cultivars through gel electrophoresis. RAPD markers, associated or not to isoenzyme analysis, were efficient to characterize peach and nectarine cultivars.

Index terms: Prunus persica, electrophoresis, isoenzymes, genetic polymorphism.

(1) Aceito para publicação em 14 de agosto de 2002. Extraído da dissertação de mestrado apresentada pelo primeiro autor à Universidade Federal de Pelotas (UFPel).

(2) Universidade Federal da Campanha, Instituto Biotecnológico de Reprodução Vegetal, Rua Flores da Cunha, 310, CEP 96400-350 Bagé, RS. E-mail: marli@alternet.com.br

(3) Embrapa-Centro de Pesquisa Agropecuária de Clima Temperado, Caixa Postal 403, CEP 96001-970 Pelotas, RS. E-mail: augustin@cpact.embrapa.br, choer@cpact.embrapa.br, bassols@cpact.embrapa.br

\section{Introdução}

Prunus persica (L.) Batsch, espécie diplóide nativa da China, com $2 n=16$ e n=8 cromossomos, é predominantemente autógama, com menos de 5\% de fecundação cruzada (Scorza et al., 1985). O pessegueiro, segundo Chandler (1942), é autofértil em relação a quase todas as cultivares, e a tendência das flores é autopolinizar-se. Embora exista variabilidade entre os genótipos, estes são, em muitos ca- 
sos, morfológica e agronomicamente muito semelhantes, o que dificulta o trabalho de identificação e caracterização. A caracterização de cultivares é extremamente importante quanto à introdução de novas variedades com a finalidade de testar a DHS (Distinção - Homogeneidade - Estabilidade), necessária para o registro e proteção de cultivares.

O Brasil possui uma área de, aproximadamente, 22.800 ha cultivada com pessegueiro, dos quais cerca de 12.000 estão localizados no Rio Grande do Sul, com uma produtividade média de 80.000 t/ano. O programa de melhoramento iniciado nesse Estado, na década de 1950, possibilitou o lançamento de grande número de cultivares, que, além de produzir frutos de melhor qualidade, permitiu a expansão da safra de 15 para 90 a 100 dias. Foi também estabelecido um Banco de Germoplasma de Prunóideas, atualmente com cerca de 850 acessos.

Nos programas de melhoramento do pessegueiro, na seleção de caracteres específicos do fruto, as plantas devem ser mantidas até o início da frutificação, geralmente durante três a quatro anos, o que torna esse processo caro e moroso. A habilidade para selecionar precocemente plantas em desenvolvimento em nível de gene, mais do que em nível de expressão do gene, economiza tempo e dinheiro, pois evita o cultivo de plantas que não possuem as características de interesse, abrindo a possibilidade de acelerar a seleção e recombinação dos indivíduos desejados. Por essas razões, os marcadores moleculares ligados a essas características são muito úteis na identificação de genótipos, antes que as características sejam expressadas (Rajapakse et al., 1995). A identificação de marcadores moleculares ligados a características economicamente importantes é muito útil no melhoramento de espécies perenes de vida longa (Warburton et al., 1996).

As isoenzimas constituem valiosos marcadores na caracterização de cultivares, além de serem tecnicamente acessíveis e de baixo custo. Recentemente, o desenvolvimento da genética molecular tem resultado em vários procedimentos baseados no DNA para a detecção de polimorfismo genético. A técnica Polimorfismo de DNA Amplificado ao Acaso (RAPD) tem sido usada, com sucesso, na identificação de cultivares (Hu \& Quiros, 1992), estimativa da diversidade genética em culturas como o pessegueiro
(Warburton \& Bliss, 1996) e construção de mapas de ligação genética (Chaparro et al., 1994).

O objetivo deste trabalho foi caracterizar cultivares de pessegueiro e nectarineira por meio de marcadores isoenzimáticos e RAPD.

\section{Material e Métodos}

Foram analisados marcadores isoenzimáticos e RAPD das cultivares de pessegueiro Granada, Eldorado, BR-1, Coral, Chinoca, Marfim, Chiripá, Della Nona, Planalto, Esmeralda, Jade, Riograndense, Maciel, Capdeboscq, Aldrighi, Precocinho, Pepita, Diamante e Turmalina, e das cultivares de nectarineira, Dulce e Anita, em pólen e folhas de plantas mantidas em campo experimental da Embrapa-Centro de Pesquisa Agropecuária de Clima Temperado, Pelotas, RS.

$\mathrm{Na}$ análise de isoenzimas, duas amostras de cada cultivar foram utilizadas. Os botões florais (balões) foram coletados nos meses de julho e agosto de 2000. As anteras foram removidas das flores e secadas, por três a cinco dias, em caixas de papel, à temperatura ambiente. $\mathrm{O}$ pólen e as anteras secas foram transferidos para tubos de eppendorf e armazenados a $-18^{\circ} \mathrm{C}$. Cinco $\mathrm{mg}$ de pólen foram homogeneizados usando $30 \mu \mathrm{L}$ de tampão de extração (0,1M Tris $\mathrm{HCl}, \mathrm{pH} 7,5$, contendo $1 \%$ de glutationa reduzida), na proporção 1:6.

As folhas foram colhidas de setembro a novembro de 2000 e estocadas em sacos de plástico a $4^{\circ} \mathrm{C}$, sendo a extração efetuada dentro de 24 horas, por maceração de 20 mg de tecido com o tampão descrito acima, na proporção 1:2. Os extratos foram absorvidos em papel filtro (Whatman 3MM) e inseridos nos orifícios do gel.

$\mathrm{Na}$ análise de isoenzimas foram usados géis de poliacrilamida, e os tampões, conforme descritos na Tabela 1. Os géis foram colocados em cubas eletroforéticas mantidas em câmara fria com uma temperatura aproximada de $4^{\circ} \mathrm{C}$. A diferença de potencial foi mantida ao redor de $10 \mathrm{~V} \mathrm{~cm}^{-1}$, até que o fronte, marcado pelo azul-debromofenol, atingisse $9 \mathrm{~cm}$ do ponto de aplicação.

Foram usados os sistemas de coloração citados por Vallejos (1983), para fosfoglucoisomerase, fosfoglucomutase, 6-fosfogluconato desidrogenase e isocitrato desidrogenase; por Scandalios (1969), para leucina aminopeptidase, fosfatase ácida e peroxidase; e por Ayala et al. (1972), para malato desidrogenase e aspartato transaminase.

Na análise de RAPD foram coletados 120 mg de folhas jovens para cada amostra. Foram realizadas duas extrações 
de DNA genômico, de duas plantas de cada uma das 21 cultivares. Os procedimentos usados na extração do DNA e separação dos fragmentos amplificados por eletroforese basearam-se em Ferreira \& Grattapaglia (1998).

A estimativa de concentração de DNA, em gel de agarose, realizou-se com base na comparação da intensidade das bandas com o padrão lambda cortado com a enzima Hind III, ficando estabelecida uma concentração final de $5 \mathrm{ng} \mu \mathrm{L}^{-1}$.

As reações de amplificação foram realizadas com volume de $13 \mu \mathrm{L}$, conforme Ferreira \& Grattaplaglia (1998), com modificações, contendo cada amostra: 3,64 $\mu \mathrm{L}$ de água pura autoclavada; $1,3 \mu \mathrm{L}$ de tampão 10x; $0,78 \mu \mathrm{L}$ de $\mathrm{MgCl}_{2}$ (50 mM); 1,04 $\mu \mathrm{L}$ de dNTPs (2,5 mM); 1,04 $\mu \mathrm{L}$ de BSA purificada ( $5 \mathrm{mg} \mathrm{mL}^{-1}$ ); 3,0 $\mu \mathrm{L}$ de primer ( $5 \mathrm{ng} \mu \mathrm{L}^{-1}$ ); $0,2 \mu \mathrm{L}$ de Taq polimerase (5 unidades $\mu \mathrm{L}^{-1}$ ); $2 \mu \mathrm{L}$ de DNA genômico ( $5 \mathrm{ng} \mu \mathrm{L}^{-1}$ ), cobertas com uma gota de óleo mineral. As amplificações foram realizadas em tubos de eppendorf em um termociclador (RoboCycler 96 Temperature Cycler - Stratagene) programado para 40 ciclos repetidos nas seguintes condições: um minuto a $92^{\circ} \mathrm{C}$ (desnaturação), um minuto a $35^{\circ} \mathrm{C}$ (anelamento) e dois minutos a $72^{\circ} \mathrm{C}$ (extensão). Após, foi efetuado um passo final de extensão de cinco minutos a $72^{\circ} \mathrm{C}$.

Os produtos das reações de amplificação foram separados por eletroforese em gel de agarose (GIBCO), submerso, na concentração de $1 \%$, com uma diferença de potencial de $5 \mathrm{~V} \mathrm{~cm}^{-1}$ por três horas, corados com brometo de etídio ( $5 \mu \mathrm{L}$ de uma solução $10 \mathrm{mg} \mathrm{mL}^{-1}$ para cada gel de $100 \mathrm{~mL}$ ), deixados para migrar por $8 \mathrm{~cm}$, e fotografados sob luz ultravioleta (302 nm) com câmera Polaroid, filme 667.

Em todos os géis foram utilizados uma prova em branco e um DNA padrão da Ladder de $1 \mathrm{~kb}(4 \mu \mathrm{L}$, na proporção marcador:tampão de extração, 1:3), com fragmentos de tamanhos conhecidos.
Um total de 50 primers, 38 provenientes dos kits OPA, OPC, OPI, OPX e OPY da Operon Technologies (Alameda, CA), e as seqüências de oligonucleotídeos: 105, 109, 110, 119, 120, 126, 173, 174, 182, 185, 195 e 197 da Universidade de British Columbia (Vancouver, Canadá), foram usados para triagem. Onze desses foram escolhidos pela resolução das bandas e pelo polimorfismo apresentado.

As análises de similaridade e de agrupamento entre as cultivares foram feitas pelo NTSYS (Numerical Taxonomy and Multivariate Analysis for Personal Computers) (Rohlf, 1989), empregando-se o coeficiente de Jaccard e o método da média aritmética não ponderada (UPGMA). Os fenogramas foram seccionados com precisão de 0,75 , para observação dos grupos formados.

\section{Resultados e Discussão}

Maior variabilidade isoenzimática foi observada em malato desidrogenase, tanto nas análises de pólen como de folhas. Elevado grau de polimorfismo desta enzima foi também observado por Messeguer et al. (1987), em pólen de cultivares de pessegueiro.

Os coeficientes de similaridade calculados com base na presença ou ausência de isoenzimas em pólen variaram entre 0,38, nas comparações de Eldorado com as cultivares Dulce, Aldrighi, Precocinho e Diamante, e 1,00, nas comparações das cultivares Coral, Chinoca e Marfim com Jade; Della Nona com Planalto; Dulce com Aldrighi; Riograndense com Anita; e Precocinho com Diamante. As cultivares foram classificadas em sete grupos (Figura 1). Messeguer et al. (1987), usando 14 sistemas enzimáticos em pólen de pessegueiro, conseguiram classificar 81 cultivares,

Tabela 1. Tampões e concentrações dos géis usados na análise de isoenzimas de 6-fosfogluconato desidrogenase (6-PGD), malato desidrogenase (MDH), isocitrato desidrogenase (IDH), leucina aminopeptidase (LAP), fosfoglucomutase (PGM), fosfoglucoisomerase (PGI), peroxidase (PRX), fosfatase ácida (FAC) e aspartato transaminase (AT) em pólen e folhas de Prunus persica (L.) Batsch.

\begin{tabular}{|c|c|c|c|c|c|}
\hline \multirow[t]{2}{*}{ Enzima } & \multirow[t]{2}{*}{ Tecido } & \multirow{2}{*}{$\begin{array}{l}\text { Concentração } \\
\text { do gel }\end{array}$} & \multicolumn{2}{|r|}{ Tampões } & \multirow[t]{2}{*}{$\mathrm{pH}$} \\
\hline & & & Eletrodos & Gel & \\
\hline 6-PGD & Pólen & $5 \%$ & $\begin{array}{l}\text { Ácido cítrico }(9,04 \mathrm{~g} / \mathrm{L}) \text {; } \\
\text { tris }(16,35 \mathrm{~g} / \mathrm{L})\end{array}$ & Histidina $(1,055 \mathrm{~g} / \mathrm{L})$ & 7,0 \\
\hline $\begin{array}{l}\text { MDH } \\
\text { IDH }\end{array}$ & $\begin{array}{l}\text { Pólen } \\
\text { Folha }\end{array}$ & $5 \%$ & Ácido cítrico $(9,04 \mathrm{~g} / \mathrm{L})$; & Histidina $(1,055 \mathrm{~g} / \mathrm{L})$ & 6,5 \\
\hline $\begin{array}{l}\text { LAP e PGM } \\
\text { PGI }\end{array}$ & $\begin{array}{l}\text { Pólen e folha } \\
\text { Folha }\end{array}$ & $5 \%$ & Citrato de sódio $(120,58$ g/L) & Histidina $(0,776 \mathrm{~g} / \mathrm{L})$ & 7,8 \\
\hline MDH e PRX & Folha & $5 \%$ & $\begin{array}{l}\text { Histidina }(10,88 \mathrm{~g} / \mathrm{L}) \text {; ácido } \\
\text { cítrico }(10,25 \mathrm{~g} / \mathrm{L})\end{array}$ & $\begin{array}{l}\text { Histidina }(1,39 \mathrm{~g} / \mathrm{L}) \text {, ácido cítrico }(0,63 \mathrm{~g} / \mathrm{L}) \\
\text { diluição do tampáo com água }(1: 6)\end{array}$ & 5,7 \\
\hline FAC & Pólen & $6 \%$ & Hidróxido de lítio $(1,20 \mathrm{~g} / \mathrm{L})$; & Nove partes trisma-base $(6,20 \mathrm{~g} / \mathrm{L})$, ácido & 8,3 \\
\hline AT & Folha & & borice & $\begin{array}{l}\text { citrico }(1,50 \mathrm{~g} / \mathrm{L}) \text { e agua destilada } \\
(1.000 \mathrm{~mL}): 1 \text { parte de tampão do eletrodo }\end{array}$ & \\
\hline
\end{tabular}


das quais 13 (17\%) tiveram um único fenótipo isoenzimático e as restantes foram agrupadas em 12 classes. Os resultados obtidos por esses autores sugerem que isoenzimas podem ser usadas como um complemento vantajoso de outras características, mas que o uso exclusivo destes marcadores não é suficiente.

Com base na análise de isoenzimas em folhas, as cultivares Esmeralda e Marfim foram as que apresentaram a menor similaridade $(0,60)$, e a maior $(1,00)$ foi encontrada nas comparações entre: Capdeboscq,

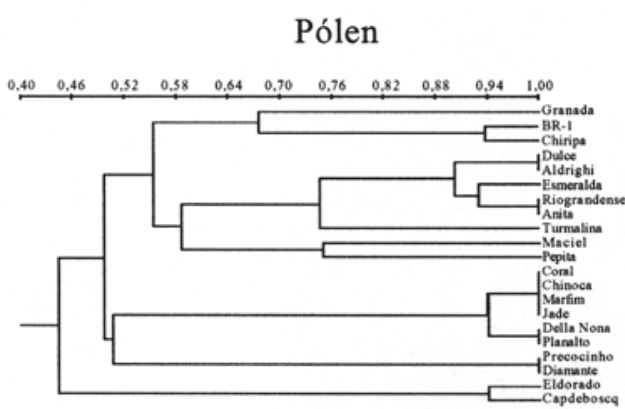

Folha

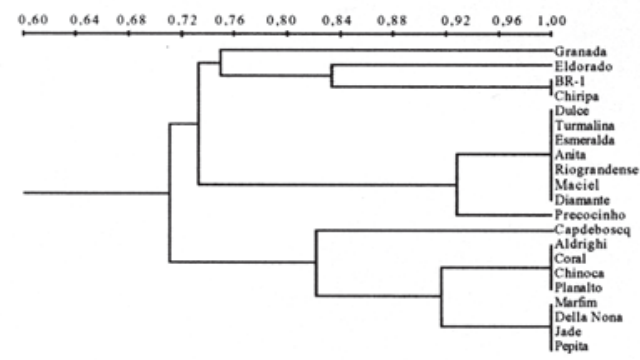

Pólen e folha

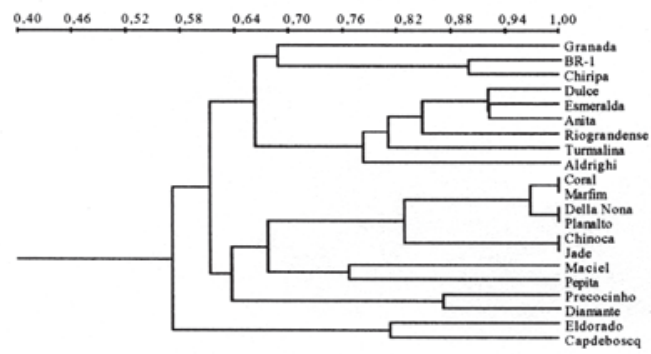

Figura 1. Fenogramas baseados nas análises de isoenzimas em pólen e folhas de cultivares de pessegueiro e nectarineira.
Eldorado, Precocinho, Diamante, Coral, Chinoca e Planalto; Riograndense, BR-1, Dulce e Anita; Aldrighi, Turmalina, Maciel e Chiripá; Pepita e Della Nona. Três grupos foram formados, indicando, portanto, que a variabilidade observada em isoenzimas em pólen é maior do que a verificada em folhas (Figura 1).

O grau de variabilidade isoenzimática pode variar em diferentes espécies do mesmo gênero. Byrne \& Littleton (1989) verificaram que essa variabilidade, em damasqueiro, é maior do que em pessegueiro, mas inferior à referida em ameixeira e amendoeira. Machado et al. (1986) não observaram polimorfismos em peroxidase e superóxido dismutase em 20 cultivares e seleções de pêssego comum, pêssego chato e nectarinas, originárias dos Estados Unidos ou desenvolvidas na Embrapa-Centro de Pesquisa Agropecuária de Clima Temperado, como possível conseqüência do sistema de reprodução da espécie, da uniformidade genética dos genótipos, de possível convergência genética, e, também, do método empregado, que permitiu apenas a análise de um pequeno número de locos. Ibañez et al. (1993) observaram pouca variabilidade em isoenzimas de esterase, peroxidase e malato desidrogenase em 26 cultivares americanas introduzidas na Argentina.

Pela análise conjunta de isoenzimas de pólen e folhas, as cultivares Aldrighi e Eldorado foram as que apresentaram a menor similaridade $(0,47)$, e a maior $(1,00)$ foi encontrada entre Marfim e Coral, Planalto e Della Nona, Jade e Chinoca. Os genótipos de pessegueiro e nectarineira foram organizados, novamente, em sete grupos; entretanto, houve uma reordenação e uma maior distinguibilidade, ficando apenas seis cultivares agrupadas duas a duas (Coral e Marfim, Della Nona e Planalto, Chinoca e Jade) (Figura 1), o que indica que as demais podem ser diferenciadas pela técnica usada.

O nível de variação isoenzimática em espécies cultivadas como o pêssego é muito baixo quando comparado com outras espécies frutíferas (Weeden \& Lamb, 1985). A baixa variação isoenzimática reflete a reduzida variabilidade genética, possivelmente como resultado do pequeno número de genótipos dos quais as cultivares atuais são originárias (Ibañez et al., 1993). Segundo Scorza et al. (1985), muitas das cultivares atuais são originárias de um pequeno grupo de ancestrais. 
Moore \& Durham (1992), em ampla revisão sobre marcadores moleculares em espécies de fruteiras perenes, referem-se ao uso de isoenzimas para identificação de genótipos, incluindo a identificação de cultivares, detecção de híbridos e determinação de taxas de cruzamento, e análise de pedigree. De acordo com esses autores, a maior dificuldade consiste na possibilidade de não haver suficiente polimorfismo isoenzimático para a identificação de cultivares, o que pode ser atribuído à inerente falta de polimorfismo, à natureza das espécies, à falta de variabilidade genética nas cultivares estudadas ou ao pequeno número de locos analisados.

Na análise de marcadores RAPD, os 11 primers utilizados geraram 79 produtos amplificados (bandas), com o número de fragmentos produzidos variando de três (Canadá 197 e OPY 05) até 15 (Canadá 173), com média de 7,18 bandas por primer. Dessas, 49 eram polimórficas (62,03\%) e 30 eram monomórficas $(37,97 \%)$ (Tabela 2$)$. Segundo Colombo et al. (1998), 10 a 30 primers, gerando de 50 a 100 bandas polimórficas, são suficientes para estimar relações genéticas dentro e entre espécies.

Cada primer usado na análise permitiu a separação das cultivares em diferentes grupos, por meio dos produtos amplificados visualizados em gel. Os primers Canadá 173, OPC-05 e OPY-13 possibilitaram a maior distinção (nove padrões) e OPY-09, a menor (três padrões) (Figura 2). Segundo Warburton et al. (1998), em um total de 60 primers utilizados na caracterização de 17 cultivares de amêndoa e uma de pêssego, apenas 21 produziram 37 bandas polimórficas. O restante (aproximadamente dois ter-

Tabela 2. Bandas monomórficas e polimórficas em cultivares de pessegueiro e nectarineira, geradas por amplificação da técnica RAPD ${ }^{(1)}$.

\begin{tabular}{llccr}
\hline \multicolumn{1}{c}{ Primer } & $\begin{array}{c}\text { Seqüência } \\
\left(5{ }^{\prime}-3^{\prime}\right)\end{array}$ & $\begin{array}{c}\text { Bandas } \\
\text { polimórficas }\end{array}$ & $\begin{array}{c}\text { Bandas } \\
\text { monomórficas }\end{array}$ & Total \\
\hline Canadá 105 & CTCGGGTGG & 5 & 2 & 7 \\
Canadá 173 & CAGGCGGCGT & 11 & 4 & 15 \\
Canadá 195 & GATCTCAGCG & 5 & 1 & 6 \\
Canadá 197 & TCCCCGTTCC & 3 & 0 & 3 \\
OPC - 05 & GATGACCGCC & 7 & 1 & 8 \\
OPI - 07 & CAGCGACAAG & 3 & 5 & 8 \\
OPX - 11 & GGAGCCTCAG & 2 & 5 & 7 \\
OPY - 05 & GGCTGCGACA & 1 & 2 & 3 \\
OPY - 07 & AGAGCCGTCA & 2 & 5 & 7 \\
OPY - 09 & AGCAGCGCAC & 3 & 2 & 5 \\
OPY - 13 & GGGTCTCGGT & 7 & 3 & 10 \\
\hline
\end{tabular}

${ }^{(1)}$ RAPD: poliformismo de DNA amplificado ao acaso. ços), produziu somente bandas monomórficas ou não amplificou.

A análise de similaridade com base em marcadores RAPD mostraram que as cultivares Aldrighi e Esmeralda foram as que apresentaram a menor similaridade $(0,23)$, ao passo que a maior $(0,98)$ foi encontrada entre Coral e Chinoca. A análise de agrupamento permitiu a separação dos genótipos em cinco grupos.

As populações de plantas autógamas geralmente são constituídas por muitas linhagens homozigotas, estreitamente aparentadas, as quais, embora existindo lado a lado, permanecem mais ou menos independentes na reprodução. Em tais populações há uma tendência a diminuir os heterozigotos, conduzindo a uma fixação de alelos e, portanto, a uma maior uniformidade genética (Machado, 1984). Observando o fenograma baseado na análise conjunta dos marcadores isoenzimáticos e RAPD (Figura 3) verifica-se uma grande uniformidade genética, excetuando-se as nectarinas Dulce e Anita, as quais são oriundas de sementes de Nova Jersey, EUA, e selecionadas na Embrapa-Centro de Pesquisa

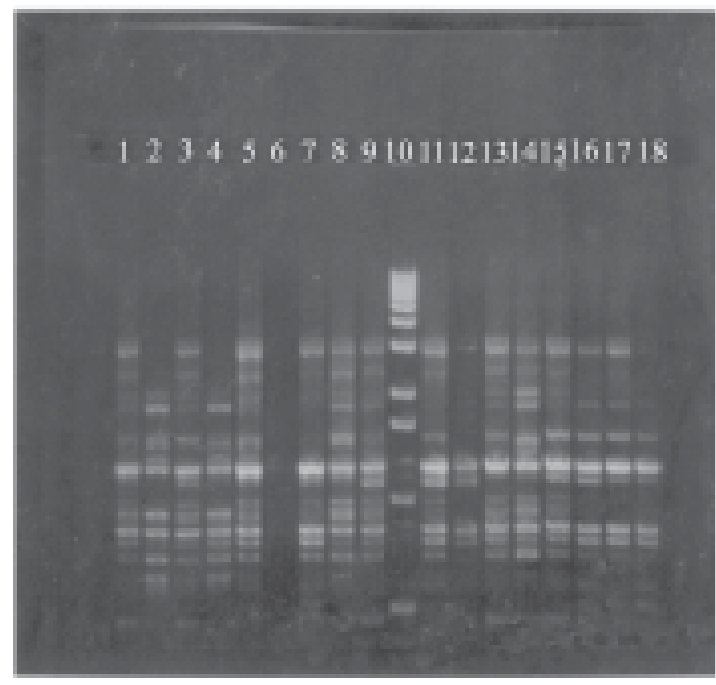

Figura 2. Produtos da amplificação gerados usando o primer 173 nas cultivares Aldrighi (1), Precocinho (2), Capdeboscq (3), Pepita (4), Diamante (5), Riograndense (7), Maciel (8), Jade (9), Turmalina (11), Eldorado (12), Granada (13), Anita (14), BR-1 (15), Coral (16), Chinoca (17), Marfim (18). Prova em branco (6), Marcador 1kb (10). 
Agropecuária de Clima Temperado. As cultivares, tipo conserva, Capdeboscq, Diamante, Esmeralda, Granada, Jade, Maciel, Pepita, Precocinho, Riograndense e Turmalina têm como ancestral próximo ou distante a cultivar Aldrighi. Intermediário, o genitor masculino de Capdeboscq, é também uma seleção de Aldrighi. A cultivar Aldrighi foi selecionada na década de 40, em Pelotas, sendo provavelmente originária de semente de pêssego importada da Argentina. BR-1, Chiripá, Marfim, Della Nona, Coral, Planalto e Chinoca têm a cultivar Delicioso em sua genealogia, seja como um dos genitores ou como um ancestral mais distante. A cultivar Delicioso é uma introdução da Estação Experimental de Pomicultura de Taquari, RS, provavelmente selecionada em pomares dos arredores de Porto Alegre. Várias das cultivares têm ancestrais originários do programa de melhoramento da Universidade de Nova Jersey. Segundo Hesse (1975), a maioria das cultivares norte-americanas é derivada de uma base um tanto limitada e, portanto, é geneticamente restrita.

\section{RAPD}

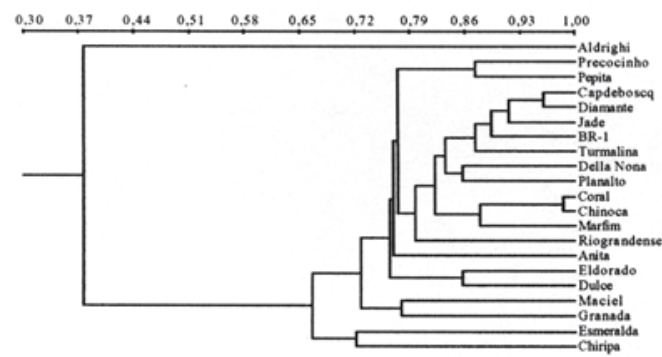

Isoenzimas e RAPD

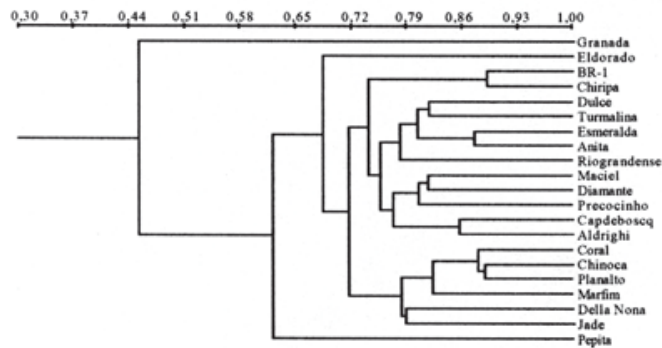

Figura 3. Fenogramas baseados na análise de marcadores RAPD e isoenzimáticos em cultivares de pessegueiro e nectarineira.

\section{Conclusões}

1. A técnica RAPD em folhas é eficiente para caracterização de cultivares de pessegueiro e de nectarineira.

2. A análise isoenzimática não é suficiente para caracterizar as cultivares de pessegueiro e de nectarineira, mas pode ser usada como método auxiliar.

\section{Agradecimentos}

Ao $\mathrm{CNPq}$, pela concessão de bolsas durante a execução do trabalho; a Beatriz Helena Gomes Rocha, pelo apoio científico; a Ema Gladis Schultz Correa, pelo apoio técnico.

\section{Referências}

AYALA, F. J.; POWELL, J. R.; TRACEY, M. L.; MOURÃO, A. C.; PÉREZ -SALAS, S. Enzyme variability in the Drosophila willistoni group - IV: genic variation in natural populations of Drosophila willistoni. Genetics, Baltimore, v. 70, p. 113-139, 1972.

BYRNE, D. H.; LITTLETON, T. G. Characterization of isozyme variability in apricots. American Society for Horticultural Science Journal, Alexandria, v. 144, n. 4 , p. 674-678, 1989.

CHANDLER, W. H. Deciduous orchards. Philadelphia: Lea \& Febiger, 1942. 438 p.

CHAPARRO, J. X.; WERNER, D. J.; O’MALLEY, D.; SEDEROFF, R. Targeted mapping and linkage analysis of morphological, isozyme, and RAPD markers in peach. Theoretical and Applied Genetics, New York, v. 87, p. 805-815, 1994.

COLOMBO, C.; SECOND, G.; VALLE, T. L.; CHARRIER, A. Genetic diversity characterization of cassava cultivars (Manihot esculenta Crantz) with RAPD markers. Genetics and Molecular Biology, Ribeirão Preto, v. 21, n. 1, p. 105-113, 1998.

FERREIRA, M. E.; GRATTAPAGLIA, D. Introdução ao uso de marcadores moleculares em análise genética. 3. ed. Brasília: Embrapa-Cenargen, 1998. 220 p.

HESSE, C. D. Peaches. In: JANICK, J.; MOORE, J. N. (Ed.). Advances in fruit breeding. West Lafayette: Purdue University Press, 1975. p. 282-355. 
HU, J.; QUIROS, C. F. Identification of broccoli and cauliflower cultivars with RAPD markers. Plant Cell Reports, New York, v. 10, p. 505-511, 1992.

IBAÑEZ, M. A.; RENZO, M. A.; POVERENE, M. M. Isozyme diversity among and within peach groups: freestone, clingstone and nectarines. Scientia Horticulturae, Amsterdam, v. 53, n. 4, p. 281-288, 1993.

MACHADO, C. A. E. Padrões isoenzimáticos de superóxido dismutase de alguns genótipos de pessegueiro Prunus persica (L.) Batsch. 1984. 36 f. Dissertação (Mestrado em Agronomia) - Universidade Federal de Pelotas, Pelotas, 1984.

MACHADO, C. A. E.; NAKASU, B. H.; OLIVEIRA, E. A.; KERSTEN, E. Padrões iosenzimáticos de superóxido dismutase de alguns genótipos de pessegueiro. Pesquisa Agropecuária Brasileira, Brasília, v. 21, n. 11, p. 11851192, nov. 1986

MESSEGUER, R.; ARÚS, P.; CARRERA, M. Identification of peach cultivars with pollen isozymes. Scientia Horticulturae, Amsterdam, v. 31, p. 107-117, 1987.

MOORE, G. A.; DURHAM, R. E. Molecular markers In: HAMMERSCHLAG, F. A.; LITZ, R. E. (Ed.). Biotechnology of perennial fruit crops. Cambridge, Inglaterra: Cambridge University Press, 1992. p. 105-139.

RAJAPAKSE, S.; BELTHOFF, L. E.; HE, G.; ESTAGER, A. E.; SCORZA, R.; VERDE, I.; BALLARD, R. E.; BAIRD, W. V.; CALLAHAN, A.; MONET, R.; ABBOTT, A. G. Genetic linkage mapping in peach using morphological, RFLP and RAPD markers. Theoretical and Applied Genetics, New York, v. 90. p. 503-510, 1995.

ROHLF, F. J. NTSYS-pc numerical taxonomy and multivariate analysis system 1.5: applied biostatistics. New York: Exeter Software, 1989. 236 p.
SCANDALIOS, J. G. Genetic control of multiple molecular forms of enzymes in plants: a review. Biochemical Genetics, New York, v. 3, p. 37-39, 1969.

SCORZA, R.; MEHLENBACHER, S. A.; LIGHTNER, G. W. Inbreeding and coancestry of freestone peach cultivars of the Eastern United States and implications for peach germoplasm improvement. American Society for Horticultural Science Journal, Alexandria, v. 110, p. 547-552, 1985.

VALLEJOS, C. E. Enzyme activity staining. In: TANKSLEY, S. D.; ORTON, T. J. (Ed.). Isozymes in plant genetics and breeding. Amsterdam: Elsevier, 1983. Part A, p. 469-515.

WARBURTON, M. L.; ARULSEKAR, S.; GRADZIEL, T. M. Genetic characterization and relatedness among California almond cultivars and breeding lines detected by random amplified polymorphic DNA (RAPD) analysis. American Society for Horticultural Science Journal, Alexandria, v. 123, n. 3, p. 381-387, 1998.

WARBURTON, M. L.; BECERRA-VELASQUEZ, V. L.; GOFFREDA, J. C.; BLISS, F. A. Utility of RAPD markers in identifying genetic linkages to genes of economic interest in peach. Theoretical and Applied Genetics, New York, v. 93, p. 920-925, 1996.

WARBURTON, M. L.; BLISS, F. A. Genetic diversity in peach (Prunus persica (L.) Batch) revealed by randomly amplified polymorphic DNA (RAPD) markers and compared to inbreeding coefficients. American Society for Horticultural Science Journal, Alexandria, v. 121, p. 1012-1019, 1996.

WEEDEN, N. F.; LAMB, R. C. Identification of apple cultivars by isozyme phenotypes. American Society for Horticultural Science Journal, Alexandria, v. 110, p. 509-515, 1985. 